\title{
Genomic diversity in pearl millet inbred lines derived from landraces and improved varieties
}

\author{
Ghislain Kanfany ${ }^{1}$, Desalegn D. Serba ${ }^{2^{*}}$ (D), Davina Rhodes ${ }^{3}$, Paul St. Amand ${ }^{4}$, Amy Bernardo ${ }^{4}$, \\ Prakash I Gangashetty ${ }^{5}$, Ndjido Ardo Kane ${ }^{6}$ and Guihua Bai ${ }^{4}$
}

\begin{abstract}
Background: Genetic improvement of pearl millet is lagging behind most of the major crops. Development of genomic resources is expected to expedite breeding for improved agronomic traits, stress tolerance, yield, and nutritional quality. Genotyping a breeding population with high throughput markers enables exploration of genetic diversity, population structure, and linkage disequilibrium (LD) which are important preludes for marker-trait association studies and application of genomic-assisted breeding.

Results: Genotyping-by-sequencing (GBS) libraries of 309 inbred lines derived from landraces and improved varieties from Africa and India generated 54,770 high quality single nucleotide polymorphism (SNP) markers. On average one SNP per $29 \mathrm{~Kb}$ was mapped in the reference genome, with the telomeric regions more densely mapped than the pericentromeric regions of the chromosomes. Population structure analysis using 30,208 SNPs evenly distributed in the genome divided 309 accessions into five subpopulations with different levels of admixture. Pairwise genetic distance (GD) between accessions varied from 0.09 to 0.33 with the average distance of 0.28 . Rapid LD decay implied low tendency of markers inherited together. Genetic differentiation estimates were the highest between subgroups 4 and 5, and the lowest between subgroups 1 and 2 .

Conclusions: Population genomic analysis of pearl millet inbred lines derived from diverse geographic and agroecological features identified five subgroups mostly following pedigree differences with different levels of admixture. It also revealed the prevalence of high genetic diversity in pearl millet, which is very useful in defining heterotic groups for hybrid breeding, trait mapping, and holds promise for improving pearl millet for yield and nutritional quality. The short LD decay observed suggests an absence of persistent haplotype blocks in pearl millet. The diverse genetic background of these lines and their low LD make this set of germplasm useful for traits mapping.
\end{abstract}

Keywords: Genetic diversity, Population structure, Pennisetum glaucum, Cenchrus americanus, Genotyping-bysequencing, SNPs, Linkage disequilibrium

\section{Background}

Pearl millet (Pennisetum glaucum (L.) R. Br. syn. Cenchrus americanus (L.) Morrone) is a climate-resilient

\footnotetext{
* Correspondence: ddserba@ksu.edu

${ }^{2}$ Agricultural Research Center-Hays, Kansas State University, 1232 240th Avenue, Hays, KS 67601, USA

Full list of author information is available at the end of the article
}

crop grown in the arid and semi-arid areas of the world. Pearl millet is the most widely grown millet species, accounting for approximately half of the total worldwide production of millets [36]. It has been traditionally grown for thousands of years for human consumption in dry areas of Africa and Asia for its higher nutritive values compared to other cereals [2]. It is well adapted

C C The Author(s). 2020 Open Access This article is licensed under a Creative Commons Attribution 4.0 International License, which permits use, sharing, adaptation, distribution and reproduction in any medium or format, as long as you give appropriate credit to the original author(s) and the source, provide a link to the Creative Commons licence, and indicate if changes were made. The images or other third party material in this article are included in the article's Creative Commons licence, unless indicated otherwise in a credit line to the material. If material is not included in the article's Creative Commons licence and your intended use is not permitted by statutory regulation or exceeds the permitted use, you will need to obtain permission directly from the copyright holder. To view a copy of this licence, visit http://creativecommons.org/licenses/by/4.0/. The Creative Commons Public Domain Dedication waiver (http://creativecommons.org/publicdomain/zero/1.0/) applies to the data made available in this article, unless otherwise stated in a credit line to the data. 
to the Sahelian and Sudanian agro-ecosystems in West and Central Africa (WCA) where other cereals have difficulty growing in the harsh environment. It has a very efficient energy production system to adapt to the hot and dry climates [39], and is even more tolerant to drought than sorghum [12].

Distressed crop production under suboptimal environmental conditions owing to global climate change is an inevitable scenario. Therefore, on top of the currently estimated $41 \%$ of the land area of arid and semiarid zones considered unsuitable for crop production [30], more land is expected to become unfavorable for crop production. Research emphasis on climate-smart crops such as pearl millet would have significant contribution in mitigation of the negative impacts of the looming climate change on food security of the dissolute environments. Although pearl millet is grown as a rainfed crop in a wide range of ecological zones and production systems, its yield is very low and spatially and temporally variable. This low productivity is predominantly attributed to limited genetic improvement and availability of improved varieties [38], along with agronomic and socioeconomic production constraints. An innovative breeding strategy is required to develop improved climate-resilient pearl millet cultivars that can contribute to a sustainable food supply for the ever-increasing population [33].

Pearl millet is also gaining a reputation as a healthpromoting nutritious grain. The grain contains vital nutrients and is considered to be equal or superior to that of wheat (Triticum aestium L.), maize (Zea mays L.), sorghum (Sorghum bicolor Moench), and rice (Oryza sativa L.) in its nutritional value [20]. It is an important source of dietary energy, and provides nutritional security for people in the most dissolute regions, particularly in WCA and Indian subcontinent. Previous studies have shown that pearl millet is an excellent source of micronutrients like iron and zinc [22]. Significant genetic variations for mineral densities and moderate heritability [29] warrant a high potential for biofortification and development of nutrient-dense foods. Tapping into this potential of pearl millet for the development of diversified foods with health benefits may provide a lowcost solution for the problems related to micronutrient deficiencies mainly in children and women who are entirely dependent on the crop as a staple food.

Development of molecular markers using next-generation sequencing technology for a breeding population is a very vital tool to expedite pearl millet improvement. Highdensity molecular markers are critical to quantitative trait loci (QTL) mapping that lays the foundation for markerassisted breeding to improve the selection efficiency for faster development of cultivars [5, 27]. Molecular markers are also used to investigate genomic-diversity and population structure of crop germplasm for systematic use in new cultivar development and germplasm conservation. With the recent advancements in next-generation sequencing (NGS) and increasingly affordable prices, profiling genome-wide DNA sequence variations, high-resolution QTL mapping, and identification of candidate genes and natural allelic variants for QTLs governing important traits have become routine practices for many crops.

Characterization of the genetic diversity and population structure of pearl millet germplasm and breeding populations is needed in order to accelerate its genetic improvement for agronomic and nutritional traits. Toward this goal, a panel of 309 inbred lines derived from landraces and improved open pollinated varieties collected from different parts of Africa and India were evaluated for population genomics using genotyping-bysequencing (GBS) markers. The present investigation employed pertinent population genomic approaches to understand the extent of genetic diversity of a pearl millet inbred lines population comprising both potential restorers and seed parents for hybrid variety development.

\section{Results \\ Development of SNP markers}

A total of $\sim 750$ million total unfiltered reads were generated from 309 inbred lines arranged in four GBS plates run twice independently on an Ion Proton Next-Generation Sequencer (ThermoFisher Scientific, Waltham, MA, US). All the raw sequence reads for all the accessions have been submitted to the National Center for Biotechnology Information (NCBI) sequence read archive and deposited under the accession ID "BioProject ID": PRJNA598172. Mapping the GBS reads to the pearl millet reference genome sequence initially detected 150, 977 unfiltered and non-imputed SNPs for the panel. Among these, 123,995 SNPs were distributed on chromosomes 1 to 7 . A total of 26,982 SNPs were mostly from the unanchored genome sequences or from the part of the genome not covered in the reference genome sequence. The raw number of SNPs mapped on each chromosome ranged from 13,432 (chr 7) to 21,665 (chr 1).

A high-density of high quality SNPs across the seven pearl millet chromosomes with most of the SNPs distributed in the telomeric regions than the pericentromeric regions of the chromosomes (Fig. 1) were visualized. Markers density varied across the genome, ranging from 0 to $192 \mathrm{SNPs}$ per $\mathrm{Mb}$ with an average of $29 \mathrm{~Kb}$ per SNP. Chromosome-wise markers density varied from 9558 (chr. 1) to 6120 (chr. 7). In chr. 5, fewer markers were mapped in one arm than the other.

Analysis of SNP types showed that transition mutations $(33,817,62 \%)$ were much higher than transversion mutations $(20,953,38 \%)$ and the transition/transversion ratio was 1.63 (Table 1). In overall, $\mathrm{C} / \mathrm{T}$ transitions occurred at the highest frequency, while $\mathrm{A} / \mathrm{T}$ mutation occurred at the lowest frequency among all types of mutations detected. The frequencies were similar between $\mathrm{A} / \mathrm{G}$ and $\mathrm{C} / \mathrm{T}$ transitions and among the four 


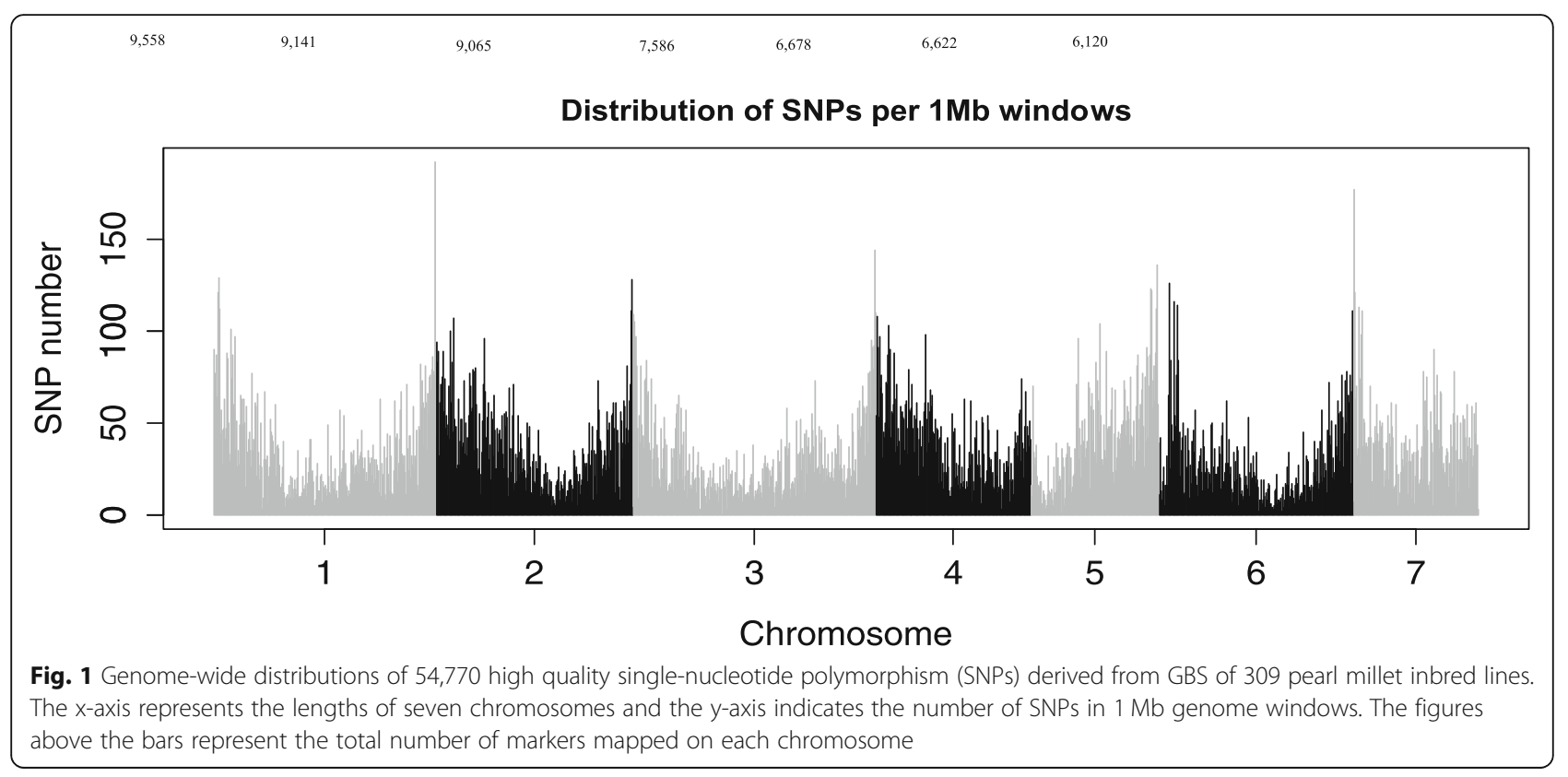

transversions, except for $\mathrm{A} / T$. minor allele frequency varied from 0.05 to 0.50 with a mean of 0.20 (Fig. 2).

\section{Genetic diversity}

A total of 54,770 SNPs on the seven chromosomes were used to evaluate genetic diversity in 309 genotypes (Additional file S2). The kinship coefficients between pairs of the 309 inbred lines ranged from 0.00 to 1.21 with a mean value of 0.02 (Fig. 3a). Nearly $91 \%$ of the pairwise relative kinship values were close to zero $(<0.05)$ and the remaining were between 0.05 and 1.21 . The highest relative kinship value was observed between ICML197354 (IP-9407) and ICML197438 (IP-17690) derived from landraces collected in Ghana and Togo, respectively (Additional file S3).

The genetic distances (GD) of pairwise comparisons of the inbred lines varied from 0.09 to 0.33 with the average distance of 0.28 (Fig. 3b). The majority of the genetic distances fell between 0.25 and 0.30 . The lowest genetic distance (0.09) was observed between ICML197458 (IP-

Table 1 Transition and transversion mutations of GBS-SNPS detected among 309 pearl millet genotypes

\begin{tabular}{lllc}
\hline Type of mutation & SNP mutation & Number of SNPs & Total SNPs per type \\
\hline Transition & A & 16,888 & 33,817 \\
Transversion & C $/ T$ & 16,929 & \\
& AT & 4180 & 20,953 \\
& A $C$ & 5434 & \\
& C/G & 5984 & \\
Total & G $/ T$ & 5355 & 54,770 \\
\hline
\end{tabular}

21020) and ICML197279 (IP-4020) developed from landraces collected in Nigeria and India, respectively (Additional file S4). The highest genetic distance (0.33) was observed between inbred ICML197314 (IP-6882) and ICML197390 (IP-11677) derived from landraces.

\section{Population structure and principal component analysis}

Analysis of the pearl millet inbred lines population using 30,893 LD pruned SNPs and the genetic distance matrix of the lines in ADMIXTURE [1] identified five subpopulations (Fig. 4a). The error rate from a cross-validation method used by Admixture to determine the appropriate number of sub-populations rapidly declined from $K=1$ to $K=5$, indicating that the 309 lines fell into five distinct groups with different levels of admixtures (Fig. 4b). Each line was assigned to a group when the proportion of the membership probability was higher than 0.6. Thus, subgroups 1 and 2 consisted of 33 and 134 lines, whereas subgroups 3,4 and 5 contained 25,14 and 10 inbred lines, respectively. The remaining 93 lines were classified as admixtures. No cluster made exclusively of inbred lines from the same country was found. In general, most of the lines closely related in pedigree or derived from landraces/improved varieties with high $\mathrm{Fe}$ and $\mathrm{Zn}$ content were grouped together, except for subgroup 2 which was formed mainly of inbred lines from the accessions collected in WCA.

To confirm the ADMIXTURE results, principal component analysis (PCA) using the snpgdsPCA function of the $\mathrm{R}$ package SNPRelate [41] and genetic relatedness among accessions was visualized using a neighbor joining (NJ) tree which revealed a clear separation between groups. Both the PCA and the NJ tree confirmed the five 


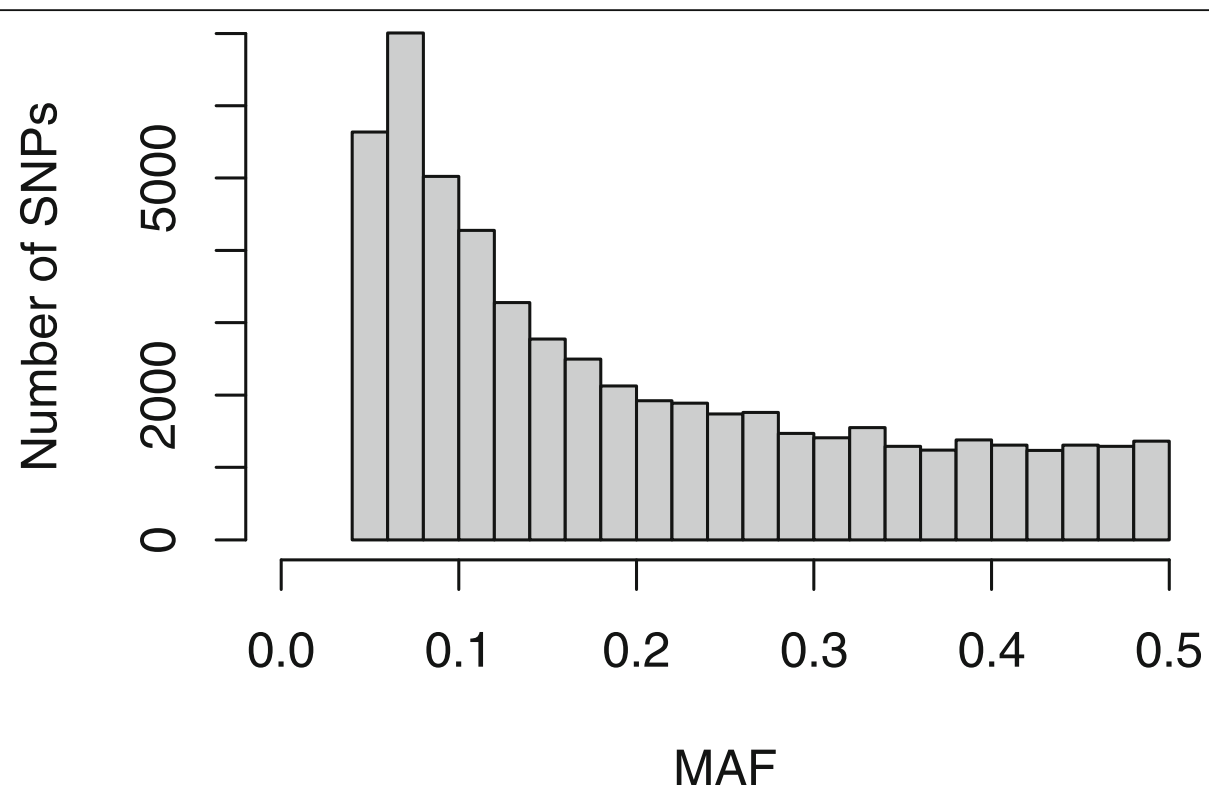

Fig. 2 Minor allele frequency (MAF) distribution for 54,770 SNP markers from 309 pearl millet inbred lines using genotyping-by-sequencing (GBS)

subgroups found in the population structure analysis (Fig. 5a and b). PCA based on the results of ADMIXTURE revealed that the total genetic variation explained by the first ten PCs was $11.3 \%$. The first and second PCs explained a very low proportion of genetic variation, 1.82 and $1.74 \%$, respectively. The results showed a clear subgroup separation in the panel and agree with the conclusion of five subgroups from ADMIXTURE. Group 3 showed more dispersion than the other groups. Based on genetic distance, the neighbor joining phylogenetic tree also displayed similar subgroups as shown by the ADMIXTURE and PCA analyses.

Among the five subgroups, subgroup 1 contained accessions such as ICTP 8203, GB8735, MC94, ICMV96490 and ICMR312, mainly known for their high levels of Fe and $\mathrm{Zn}$ content. Subgroup 2 was composed of landraces/ improved cultivars mainly from WCA countries. Subgroup 3 was formed with inbred lines derived from landraces/improved cultivars collected from various sources, and showed more dispersion than the other subgroups. Results showed that the subgroup 4 contained inbred lines derived from the source populations IP-3110, IP-6745, IP21142, PBPMPOP-1 and PBPMPOP-2, whereas group 5 comprised about $50 \%$ of inbred lines extracted from PBPMPOP-3.

\section{Allelic diversity and purity}

In accordance with the neutral allele distribution expected for inbred populations, the nucleotide diversity $(\pi)$ and Tajima's D statistics among the five subpopulations were presented in Table 2. Degrees of SNP heterozygosity varied from 0 to $100 \%$ with an average of $15 \%$
(Fig. 6a). Most of the SNPs had a heterozygosity range of $0-25 \%$. Similarly, genetic purity of the lines in the population varied from 70 to $93 \%$, with a mean of $85 \%$ (Fig. 6b). Out of 309 inbred lines, 105 (34\%) showed less than $10 \%$ heterozygosity, $145(47 \%)$ had heterozygosity ranging from 11 to $20 \%$, while 59 (about 20\%) had heterozygosity from 21 to $30 \%$.

\section{Genetic differentiation}

Genetic differentiation of subgroups was calculated using $\mathrm{F}_{\text {st }}$-based analysis of the SNP data (Table 3). The Fst coefficients showed that subgroup 2 could be considered as a subset of the whole panel used in this study with a very low Fst value as compared to the whole population (0.002). The Fst coefficients among the groups varied from 0.044 to 0.110 , indicating moderate differentiation. The highest level of differentiation was observed between subgroups 4 and 5. In contrast, the lowest Fst coefficient was observed between subgroups 2 and 3 .

The mean nucleotide diversity observed in subgroup 2 (9.77E-06) was similar to the whole panel (9.92E-06) (Table 3). The nucleotide diversity among accessions within the subgroups ranged from 7.32E-06 to 9.77E-06. Accessions from Group 5 showed lowest diversity in the population. The mean Tajima's D values were positive for all the subgroups, which is an indication for balancing selection.

\section{Linkage disequilibrium}

LD among the SNPs was investigated between pairs of SNP markers from the seven chromosomes and then between pairs of SNP markers from the same 


\section{Kinship}

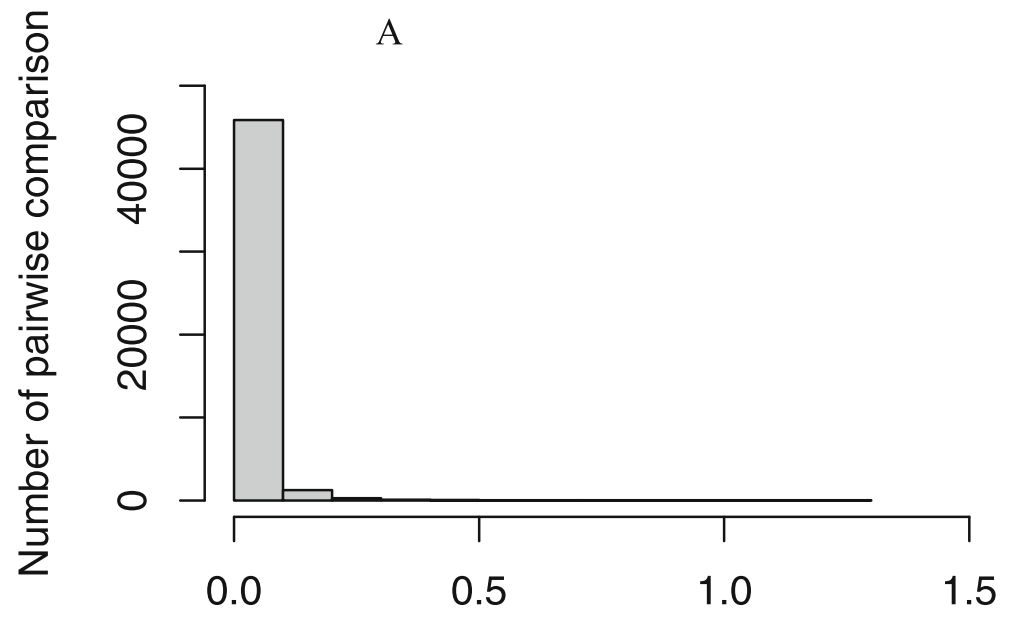

Kinship coeffcient

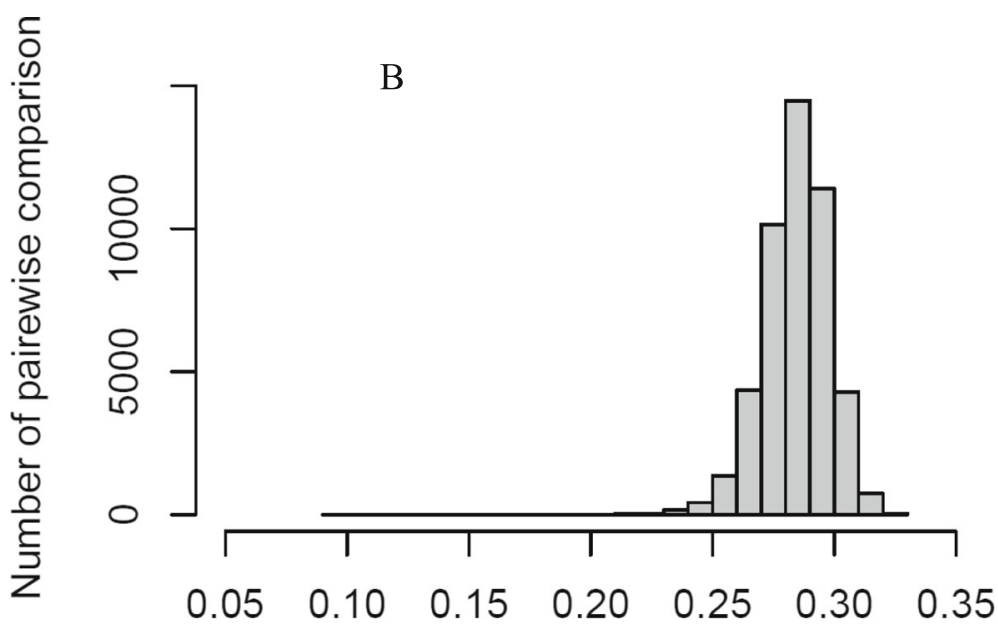

Genetic distance

Fig. 3 Pairwise relative kinship (a) and genetic distance (b) of 309 pearl millet genotypes using 54,770 high quality SNP markers developed using genotyping-by-sequencing (GBS)

chromosome. The average pairwise LD $\left(\mathrm{r}^{2}\right)$ across the genome declined rapidly with increasing physical distance and most of the $\mathrm{r}^{2}$ values were below 0.05 (Fig. 7). On average, LD declined from its initial value of 0.46 to 0.1 within approximately $3.5 \mathrm{~kb}$. LD decays rapidly in chromosomes 1 and $4(\sim 1.5 \mathrm{~kb})$ as compared to 3 and $7(\sim 7.2 \mathrm{~kb})$, suggesting that a larger number of markers are required from chromosomes 1 and 4 than from chromosomes 3 and 7 for genome-wide association studies in pearl millet.

\section{Discussion}

SNPs have become the markers of choice in genetics and evolutionary biology studies, as well as in applications for marker-assisted selection in plant breeding.
High-density of markers on a large numbers of individuals is vital for precise quantitative trait locus (QTL) mapping and association analysis [4]. GBS is a NGS based genotyping platform [14] that has the advantage of reduced genome representation to enable highthroughput genome-wide SNP genotyping with an affordable cost.

In this study, 309 pearl millet inbred lines were genotyped using GBS. Using the pearl millet genome [37] as a reference and filtering the dataset resulted in the development of 54,770 high quality genome-wide SNPs. The level of heterozygosity of the SNPs ranged from of 0 to $20 \%$ with an average of $15 \%$. Since we pooled $4-6$ plants for genomic DNA extraction, this level of 
A $\quad k=4$
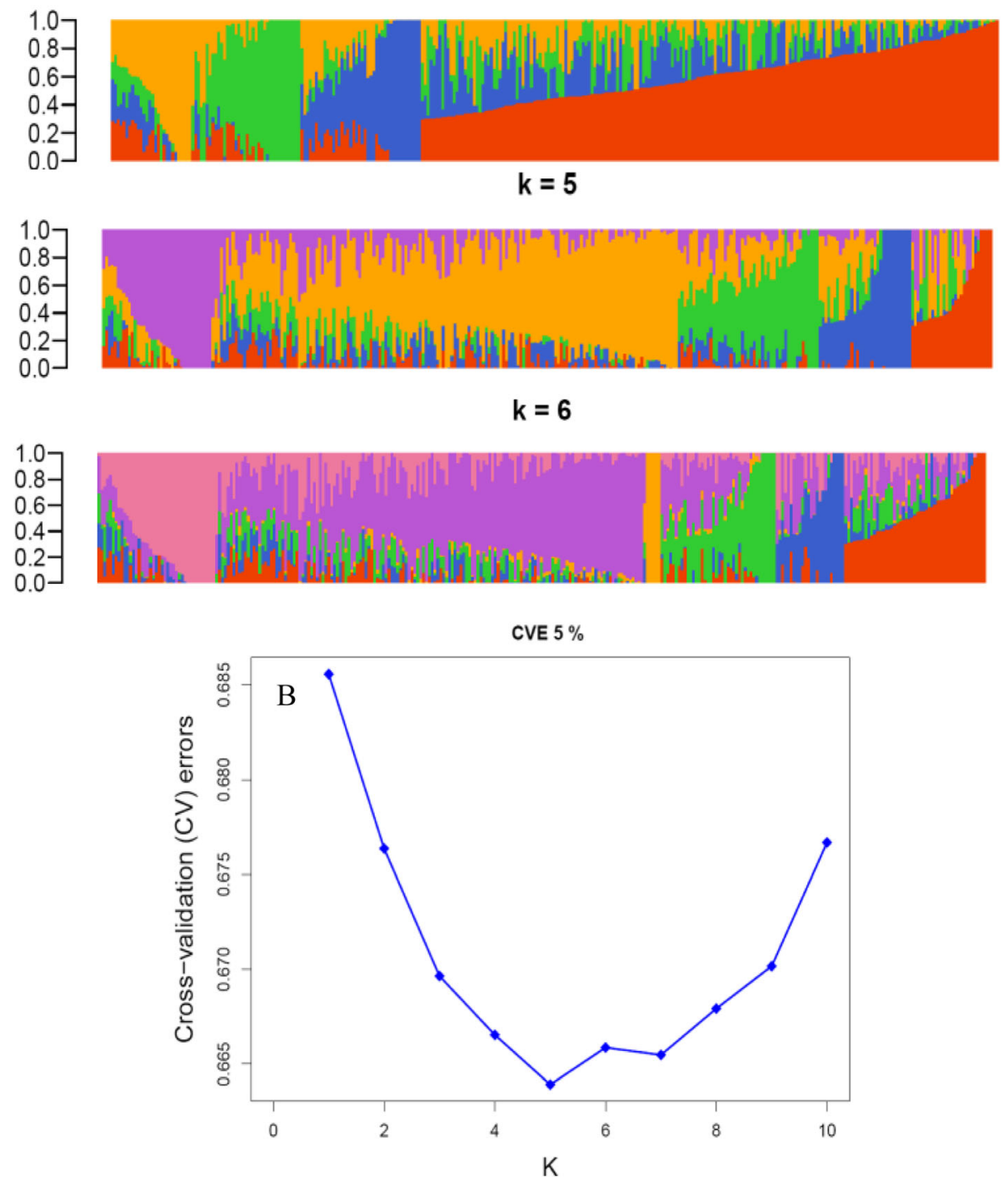

Fig. 4 Population structure of 309 pearl millet inbred lines. a Bayesian posterior probability of membership determined by the model-based clustering method for hypothetical subpopulations, $\mathrm{K}$ values of 1-10. The color of the vertical bar on the $\mathrm{x}$-axis represents the proportion of membership of each inbred line in each subgroup. b Cross-validation (CV) errors suggest that the 309 genotypes can be divided into five true genetic populations

heterozygosity may be attributed to the heterogeneity of plants within an accession. It has also been reported that high outcrossing rates, a sequencing error or mapping error may lead to high heterozygosity in pearl millet [19]. The level of homozygosity of the genotypes ranged from 70 to $93 \%$, with an average of $85 \%$, which is expected for inbred lines.

Genome-wide marker density analysis across the chromosome arms identified an average of 35 SNPs per Mb (1 SNP per $29 \mathrm{~Kb}$ ) of genome size. This SNP density is slightly lower than the previously reported 48 SNPs per $\mathrm{Mb}$ of genome [32]. The report revealed that the distribution of the SNPs was dense in the telomeric regions than the pericentromeric regions of the pearl millet chromosomes probably because of low recombination rates, low gene density and/or low restriction sites for the enzymes around the centromere. In pearl millet, the location of each centromere has not been determined. Therefore, the low SNP density in one arm of chromosome 5 is possibly associated with the location of centromere. This phenomenon can also be attributed to decreased restriction enzyme sites in this genome region, or fewer polymorphisms related to interactions of different causes of genetic variation such as mutation, selection, recombination, and genetic-drift which shape nucleotide polymorphisms across the genome $[3,10,11,16]$. Low gene density, which is associated with 

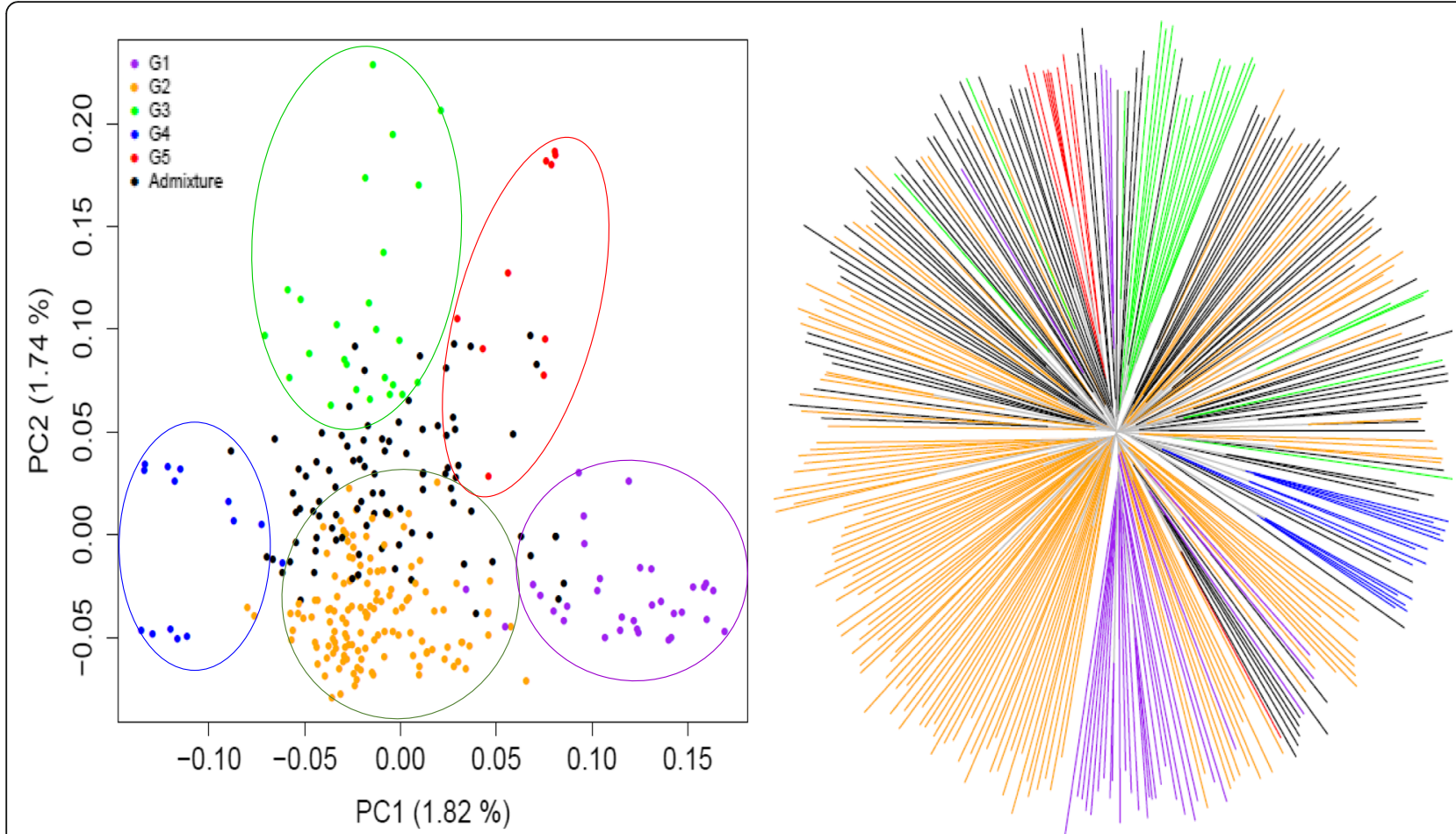

Fig. 5 The principal component analysis (a) and neighbor joining tree (b) of 309 pearl millet inbred lines. The branch colors indicate genotypes corresponding to the subpopulations (Subpopulations 1 to 5) from the population structure analysis in Fig. 4. Five clades were distinguished by distance between branches

low nucleotide diversity [15], and decreased natural and artificial selection for alleles located in this part of the genome are both additional plausible reasons for lower marker numbers.

Germplasm resources and the genetic diversity of a crop species have paramount importance in the genetic improvement of a crop for desirable traits and conservation of genetic resources. Nucleotide polymorphism is a measure of genetic diversity and a key to understanding the effect of past selective forces on the gene pool. Average nucleotide diversity in the whole panel was 0.28 in this study, which was higher than reported for a global collection [19], but lower than the mean gene diversity (0.54) estimated using simple sequence repeat (SSR) markers in a pearl millet inbred germplasm association panel (PMiGAP) [31]. As adaptive evolution is implicated in reducing functional diversity [18], genetic distance among inbred lines derived from landraces grown in similar environments is expected to be low. Nevertheless, ecology and evolution work together to determine the population stability and maintain diversity within and among populations [21].

Population structure is a very important part of evolutionary genetics and depicts the diversity of a metapopulation that might have evolved independently. Knowledge about the genetic diversity and the population structure of a crop has important implications for a genome-wide association study. In the present study, population structure analysis using 30,893 SNPs detected five subgroups in a panel of 309 inbred lines and the grouping basically matches pedigree relationships or the parental source of the inbred lines. This number of subpopulations was validated by graphing kinship against the cross-validation error. Some genetic diversity studies reported six subpopulations in different panels of pearl millet [31, 32]. A population genomics study conducted on a collection of landraces from Senegal in comparison with a global collections, observed more diversity in the former [19], settling the West African origin of pearl millet [8]. Multiple factors such as natural selection, migration, and genetic drift might be the mechanisms that caused changes in allele frequencies over time and acted as forces for genetic diversification and population structure formation [9]. Grouping of pearl millet inbred lines from the same geographic region into different subpopulations implies that selection for different traits is maintaining genetic diversity.

A wide range of genotypic variations are prevalent in pearl millet for various agronomic traits and stress tolerance as a result of its cultivation in diverse agro-climatic conditions and soil types [34]. However, a limited amount of germplasm has been exploited in breeding to improve its agronomic traits, stress tolerance, and 

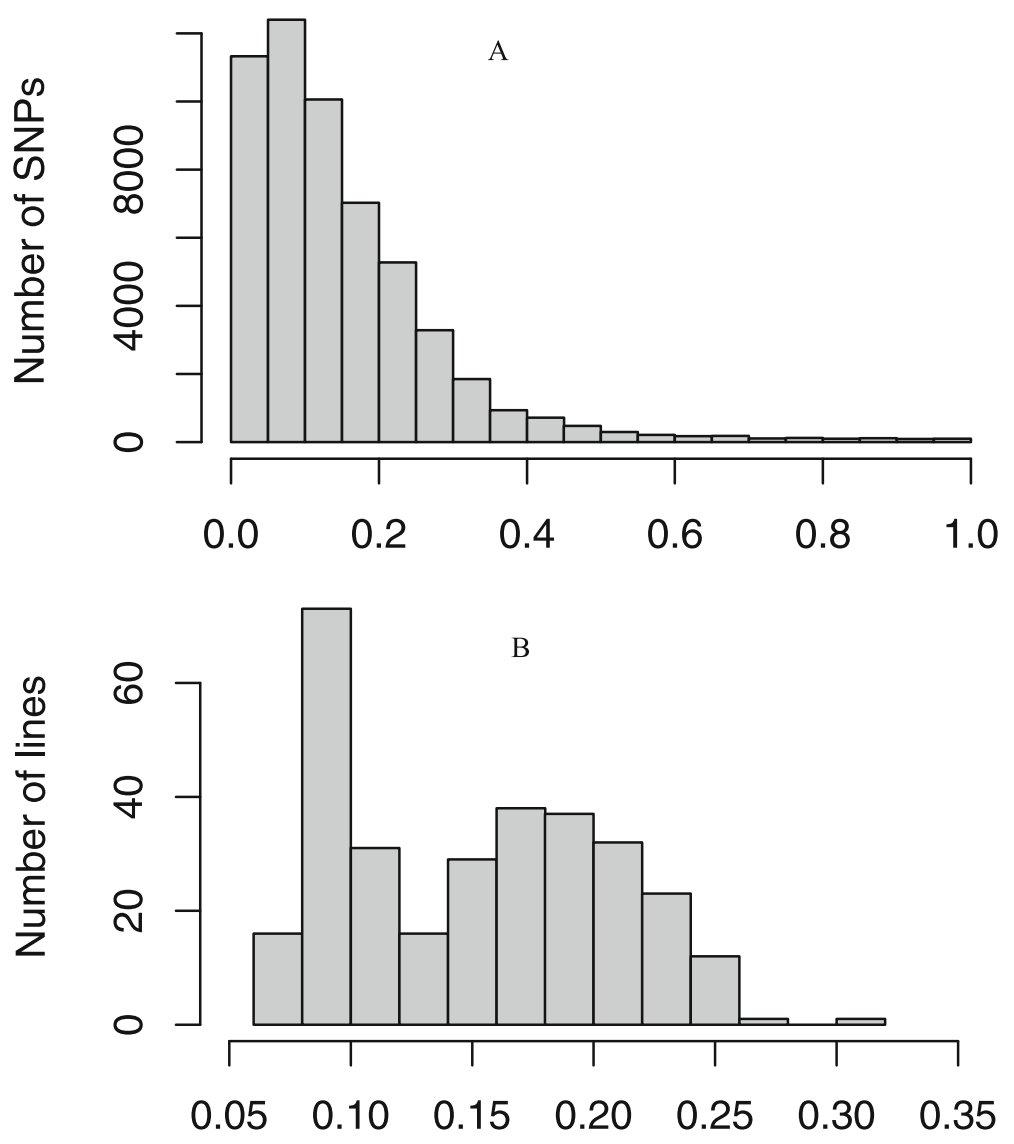

Heterozygosity

Fig. 6 Single Nucleotide polymorphism (SNP) (a) and taxa heterozygosity (b) for 54,770 genome-wide SNPs markers detected among 309 pearl millet inbred lines

productivity in pearl millet [28]. Only a limited number of studies have assessed the evolutionary dynamics and genetic diversity patterns in pearl millet. Genetic characterization of early- and late-flowering landraces from Senegal also indicated a large diversity in Senegalese pearl millet germplasm that may be useful in

Table 2 The nucleotide diversity ( $\pi$ ) and Tajima's D statistics among 309 pearl millet inbred lines grouped into five subpopulations

\begin{tabular}{llllllll}
\hline \multirow{2}{*}{ Population/Group } & \multicolumn{3}{l}{ Nucleotide diversity $(\pi)$} & & \multicolumn{3}{c}{ Tajima's D } \\
\cline { 2 - 3 } & Mean & Min & Max & & Mean & Min & Max \\
\hline Whole Population & $9.92 \mathrm{E}-06$ & $1.32 \mathrm{E}-07$ & $5.89 \mathrm{E}-05$ & & 2.383 & -0.367 & 5.102 \\
Subgroup 1 & $8.78 \mathrm{E}-06$ & $1.16 \mathrm{E}-07$ & $5.13 \mathrm{E}-05$ & & 0.804 & -1.833 & 3.304 \\
Subgroup 2 & $9.77 \mathrm{E}-06$ & $1.26 \mathrm{E}-07$ & $5.65 \mathrm{E}-05$ & & 1.857 & -1.237 & 4.227 \\
Subgroup 3 & $9.25 \mathrm{E}-06$ & $1.50 \mathrm{E}-07$ & $5.58 \mathrm{E}-05$ & & 0.845 & -1.452 & 3.274 \\
Subgroup 4 & $9.24 \mathrm{E}-06$ & $7.14 \mathrm{E}-08$ & $5.61 \mathrm{E}-05$ & & 0.713 & -1.687 & 3.149 \\
Subgroup 5 & $7.32 \mathrm{E}-06$ & $1.00 \mathrm{E}-07$ & $4.90 \mathrm{E}-05$ & & 0.269 & -1.897 & 2.477 \\
\hline
\end{tabular}

defining heterotic groups and formation of a genomic association panels for trait mapping [13]. This study provides a survey of genetic variation in pearl millet inbred lines from different geographic regions in Africa and Asia representing various agroecological niches. However, as the inbred lines were developed from landraces, improved varieties, and crosses between different genotypes, correlation of the subgroups to geographic origin could not be made.

Genetic patterns in the natural plant populations shows their biological importance in the ecology and economic prominence in agriculture [24]. In pearl millet, genetic differentiation is important in the genetic improvement of the crop for productivity and adaptation in the agriculturally marginal environments. The genetic differentiation observed in the current study is the reflection of the extent of genetic variation among the landraces and improved varieties grown in different areas. The population structure analysis revealed five subgroups that mostly followed pedigree differences. As 
Table $3 \mathrm{~F}_{\mathrm{ST}}$ among the five sub-populations determined by population structure analysis and the whole panel

\begin{tabular}{lllll}
\hline & Population & Subgroup 1 & Subgroup 2 & Subgroup 3 \\
\hline Subgroup 1 & 0.027 & & & \\
Subgroup 2 & 0.002 & 0.040 & & \\
Subgroup 3 & 0.025 & 0.062 & 0.044 & 0.071 \\
Subgroup 4 & 0.044 & 0.090 & 0.055 & 0.076 \\
Subgroup 5 & 0.052 & 0.086 & 0.066 & 0.110 \\
\hline
\end{tabular}

pedigree is the reflection of geographic origin of the parents involved and selection history of the inbred lines, growing environment may had significant role in the formation of distinct forms that are distantly related. However, the $F_{s t}$ values between the subgroups showed moderate differentiation. A previous study conducted in Niger revealed also a moderate level of differenciation on cultivated pearl millet accessions compared to the wild populations [25]. This variation at the DNA sequence level is important in the formation of preliminary heterotic groups through intra and inter-cluster crossing and subsequent studies to maximize hybrid performance.

\section{Conclusions}

A better understanding of genetic diversity in pearl millet enhances the use of available germplasm for breeding and systematic conservation. Screening 309 pearl millet lines with 54,770 high quality genome-wide SNPs revealed that genetic diversity is preserved in pearl millet inbred lines from Africa and the Indian subcontinent. Population structure analysis detected five subpopulations that are mostly a reflection pedigree relationship. Population diversity analysis using $F_{s t}$ revealed moderate differentiation among the five subpopulations. The nucleotide diversity and Tajima's D statistics showed low diversity in subgroup 5, but high diversity in the other four subgroups. The genomic resources developed in this study can significantly contribute to the application of genomic-assisted breeding in pearl millet, especially in heterotic grouping and hybrid breeding.

\section{Methods}

Plant materials

A total of 309 inbred lines obtained from International Crop Research in Semi-Arid Tropics (ICRISAT-Niger) were used in this study (Additional file S1). The inbred lines were developed following 4 to 6 generations of selfing of landraces originating from WCA countries and Asia, and improved open pollinated varieties (OPV) with improved iron $(\mathrm{Fe})$ and zinc $(\mathrm{Zn})$ content.

\section{DNA extraction, library construction, and genotyping}

The seeds of the inbred lines were planted in a 96-cell trays in a greenhouse at Kansas State University. Fresh leaf tissues pooled from four to six seedlings per line were collected 7 days after planting, and freeze-dried for $48 \mathrm{~h}$ to remove water rapidly. Genomic DNA was extracted following a modified $2 \%$ CTAB protocol as previously described [32]. DNA was quantified using Quant$\mathrm{iT}^{\mathrm{m} \mathrm{M}}$ PicoGreen $^{\circ}$ dsDNA assay kit (Thermo Scientific, Waltham, MA, USA) on a FLUOstar Omega

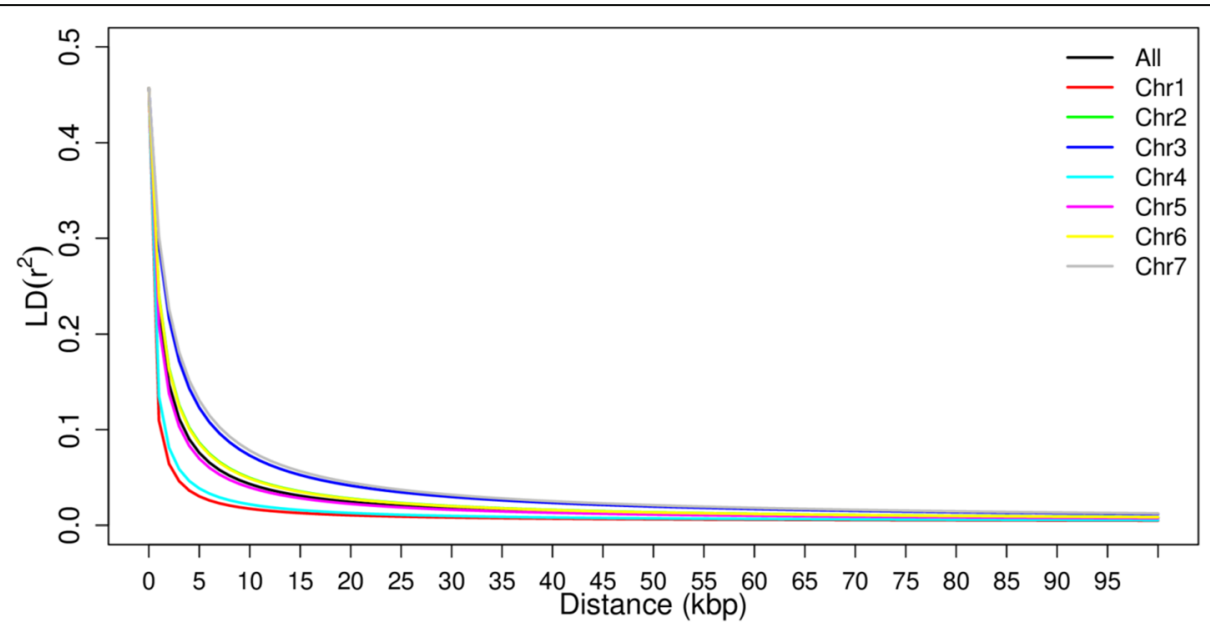

Fig. 7 Chromosome-based LD (r2) decay of seven chromosomes in 309 pearl millet inbred lines using 54,770 high quality SNP markers developed using genotyping-by-sequencing (GBS) 
fluorescence plate reader (BMG LABTECH, Cary, NC, USA) and normalized to $25 \mathrm{ng} / \mathrm{ul}$ with $10 \mathrm{mM}$ TRIS.

For library construction, $200 \mathrm{ng}$ of DNA was double digested with PstI (5'-CTGCA/G-3') and MspI (5'-C/ CGG-3') restriction enzymes (New England Biolabs, Ipswitch, MA, USA). Then the GBS [14] libraries were constructed following Mascher et al. [26]. The DNA fragments from each sample were ligated to unique barcoded-adapters for identification and multiplexing of samples for DNA sequencing and analysis. GBS libraries were sequenced twice on an Ion Torrent Proton Sequencer (ThermoFisher Scientific, Waltham, MA, USA) at the USDA-ARS Central Small Grain Genotyping Laboratory at Kansas State University, Manhattan, Kansas.

\section{SNP calling and filtering}

The sequencing runs generated a total of 750.2 million reads. The pearl millet reference genome (https://cegresources.icrisat.org/data_public/PearlMillet_Genome/v1.1 ) [37] was used to map GBS reads and identify SNPs using TASSEL 5.0 GBSv2 pipeline, (www.maizegenetics. net) [6]. The mapping of reads to the pearl millet reference genome was done using BWA version 0.7.17-r1188 [23]. An 80 bases poly-A tail was added to the 3' end of all the sequencing reads to avoid discarding short reads. The alignment detected a total of 150,977 raw SNP data points with a minimum SNP locus coverage of 0.19 and a minimum minor allele frequency of 0.0097 . Then, the SNPs were filtered to remove those with unknown locations, indels, a minor allele frequency (MAF) of $<5 \%$ and a maximum missing data of $20 \%$. Missing data for the remaining 115,772 SNPs were imputed using Beagle V5.1 [7] using the default parameters. A total of 54,770 SNPs (47\% of the initial SNPs data points) were used for further statistical analyses. Population structure and PCA analysis were conducted with 30,208 evenly distributed SNPs that were randomly selected from the filtered SNP dataset.

\section{Data analysis}

Genotype and taxa summaries (markers distribution, MAF, SNP heterozygosity, genetic distance, genetic purity, pairwise comparison and Kinship matrix) were calculated using TASSEL v.5 software [6]. Population structure of the SNP genotype datasets was analyzed using ADMIXTURE software [1] for $\mathrm{K}=1$ to 10 . An accession was assigned to a subpopulation when the proportion of coefficient of membership to a subpopulation was greater than $60 \%$. To confirm the admixture results, PCA was performed using the snpgdsPCA function of the R package SNPRelate [41].

LD analysis was performed using TASSEL as a standardized disequilibrium coefficient ( $D^{\prime}$ ) [17] and squared allele-frequency correlations $\left(\mathrm{r}^{2}\right)$ [40] among pairs of loci. LD decay was fitted using a nonlinear $l s$ function in
R. Genetic difference among the identified subgroups were determined using Fst across the SNPs as a measure of population differentiation due to genetic structure. DNA sequence variation within and between populations was estimated by analyzing the genetic diversity (pi) and Tadjima's D [35] in a sliding window size of $1 \mathrm{Mbp}$.

\section{Supplementary information}

Supplementary information accompanies this paper at https://doi.org/10. 1186/s12864-020-06796-4.

Additional file 1. List of materials with their pedigree and origin.

Additional file 2. SNP markers $(54,770)$ developed for 309 pearl millet inbred lines.

Additional file 3. Relative kinship among pairs of inbred lines. (CSV $1417 \mathrm{~kb})$

Additional file 4. Genetic distance among pairs of inbred lines. (CSV $1611 \mathrm{~kb})$

\section{Abbreviations}

A: Adenine; C: Cytosine; Chr: Chromosome; CTAB: Cetyl Trimethyl Ammonium Bromide; DNA: Deoxyribonucleic Acid,; Fe: Iron; G: Guanine; GBS: Genotyping-by-sequencing; GD: Genetic distance; ICRISAT: International Crops Research Institute for the Semi-Arid Tropics; LD: Linkage disequilibrium; MAF: minor allele frequency; NCBI: National Center for Biotechnology Information; NGS: Next-generation sequencing; NJ: Neighbor joining; OPV: Open pollinated variety; PCA: Principal component analysis; QTL: Quantitative trait locus/loci; SNP: single ne; T: Thymine; TRIS: Tris (hydroxymethyl) aminomethane; USDA-ARS: United States Department of Agriculture-Agricultural Research Service; WCA: West and Central Africa; Zn: Zinc

\section{Acknowledgments}

Mention of trade names or commercial products in this publication is solely for the purpose of providing specific information and does not imply recommendation or endorsement by any part herein. This is contribution number 20-185-J from the Kansas Agricultural Experiment Station.

\section{Authors' contributions}

GK and DDS initiated the project, designed the research framework, analyzed the data and drafted the manuscript; PSA, AB, and GK carried out the GBS and processed the sequence data; DR and GB managed the laboratory and edited the manuscript; PG provided the experimental materials; NAK

organized the materials. All authors read and approved the final manuscript.

\section{Funding}

Funding for this research was provided by the United States Department of Agriculture Foreign Agricultural Service through the 2019 Norman E. Borlaug International Agricultural Science and Technology Fellowship Program (NOFO\#: USDA-FAS-10777-0700-10.-19-0010). USDA is an equal opportunity provider and employer.

\section{Availability of data and materials}

All the raw sequencing reads for all the accessions have been submitted to the National Centre for Biotechnology Information (NCBI) sequence read archive and deposited under the accession ID or "BioProject ID":

PRJNA598172. The SNP markers developed in this study were included as a supplementary information with this paper (Additional file S2).

\section{Ethics approval and consent to participate} Not applicable.

\section{Consent for publication}

Not applicable.

\section{Competing interests}

The authors declare that they have no competing interests. 


\section{Author details}

${ }^{1}$ Institut Sénégalais de Recherches Agricoles (ISRA), Centre National de Recherches Agronomiques de Bambey, Diourbel, Senegal. ${ }^{2}$ Agricultural Research Center-Hays, Kansas State University, 1232 240th Avenue, Hays, KS 67601, USA. ${ }^{3}$ Department of Agronomy, Kansas State University, Manhattan, KS, USA. ${ }^{4}$ Hard Winter Wheat Genetics Research Unit, USDA-ARS, Manhattan, KS, USA. International Crops Research Institute for the Semi-Arid Tropics (ICRISAT), Niamey, Niger. ${ }^{6}$ Institut Sénégalais de Recherches Agricoles/Centre d'Étude Régional pour l'Amélioration de l'Adaptation à la Sécheresse (ISRA/ (ERAAS), Thiès, Senegal.

\section{Received: 31 January 2020 Accepted: 26 May 2020} Published online: 08 July 2020

\section{References}

1. Alexander DH, Novembre J, Lange K. Fast model-based estimation of ancestry in unrelated individuals. Genome Res. 2009;19(9):1655-64.

2. Amadou I, Gounga ME, Le GW. Millets: nutritional composition, some health benefits and processing - a review. Emir J Food Agri. 2013;25(7):501-8.

3. Begun DJ, Aquadro CF. Levels of naturally occurring DNA polymorphism correlate with recombination rates in D. melanogaster. 1992, Nature; 356(6369):519-20 Available at https://doi.org/10.1038/356519a0.

4. Beissinger TM, Hirsch CN, Sekhon RS, Foerster JM, Johnson JM, Muttoni G, Vaillancourt B, Buell CR, Kaeppler SM, de Leon N. Marker density and read depth for genotyping populations using genotyping-by-sequencing. Genetics. 2013;193(4):1073 LP - 1081 Available at http://www.genetics.org/ content/193/4/1073.abstract.

5. Bevan MW, Uauy C. Genomics reveals new landscapes for crop improvement. Genome Biol. 2013;14(6):206.

6. Bradbury PJ, Zhang Z, Kroon DE, Casstevens TM, Ramdoss Y, Buckler ES. TASSEL: software for association mapping of complex traits in diverse samples. Bioinformatics. 2007;23(19):2633-5.

7. Browning SR, Browning BL. Rapid and accurate haplotype phasing and missing-data inference for whole-genome association studies by use of localized haplotype clustering. Am. J. Hum. Genet. 2007;81(5):1084-97 Available at https://doi.org/10.1086/521987.

8. Burgarella C, Cubry P, Kane NA, Varshney RK, Mariac C, Liu X, Shi C, Thudi M, Couderc M, Xu X, Chitikineni A, Scarcelli N, Barnaud A, Rhoné B, Dupuy C, François O, Berthouly-Salazar C, Vigouroux Y. A western Sahara Centre of domestication inferred from pearl millet genomes. Nat Ecol Evol. 2018;2:1377-80.

9. Cortázar-Chinarro M, Lattenkamp EZ, Meyer-Lucht Y, Luquet E, Laurila A, Höglund J. Drift, selection, or migration? Processes affecting genetic differentiation and variation along a latitudinal gradient in an amphibian. BMC Evol. Biol. 2017;17(1):189 Available at https://www.ncbi.nlm.nih.gov/ pubmed/28806900.

10. Cruickshank TE, Hahn MW. Reanalysis suggests that genomic islands of speciation are due to reduced diversity, not reduced gene flow. Mol Ecol. 2014;23(13):3133-57.

11. Cutter AD, Payseur BA. Genomic signatures of selection at linked sites: unifying the disparity among species. Nat. Rev. Genet. 2013;14(4):262-74 Available at https://doi.org/10.1038/nrg3425.

12. Dave, H.R. 1987. Pearl millet hybrids. p. 121-126. In Witcombe, J.R., Beckerman, S.R. (eds.), proceedings of the international pearl millet workshop. ICRISAT, Patancheru, a.P. 502 324, India.

13. Diack O, Kane NA, Berthouly-Salazar C, Gueye MC, Diop BM, Fofana A, Sy O, Tall H, Zekraoui L, Piquet M, Couderc M, Vigouroux Y, Diouf D, Barnaud A. New genetic insights into pearl millet diversity as revealed by characterization of early- and late-flowering landraces from Senegal. Front Plant Sci. 2017:8:1-9.

14. Elshire RJ, Glaubitz JC, Sun Q, Poland JA, Kawamoto K, Buckler ES, Mitchell SE. A robust, simple genotyping-by-sequencing (GBS) approach for high diversity species. PLoS One. 2011;6(5):e19379.

15. Flowers JM, Molina J, Rubinstein S, Huang P, Schaal BA, Purugganan MD. Natural selection in gene-dense regions shapes the genomic pattern of polymorphism in wild and domesticated Rice. Mol. Biol. Evol. 2011;29(2): 675-87 Available at https://doi.org/10.1093/molbev/msr225.

16. Gosset CC, Bierne N. Differential introgression from a sister species explains high FST outlier loci within a mussel species. J Evol Biol. 2013;26(1):14-26.

17. Hedrick PW. Gametic disequilibrium measures: proceed with caution. Genetics. 1987;117(2):331 LP - 341 Available at http://www.genetics.org/ content/117/2/331.abstract.
18. Hoelzel AR, Bruford MW, Fleischer RC. Conservation of adaptive potential and functional diversity. Conserv. Genet. 2019;20(1):1-5 Available at https:// doi.org/10.1007/s10592-019-01151-x.

19. Hu Z, Mbacké B, Perumal R, Guèye MC, Sy O, Bouchet S, Prasad PW, Morris GP. Population genomics of pearl millet (Pennisetum glaucum (L.) R. Br.): comparative analysis of global accessions and Senegalese landraces. Bmc Genomics. 2015;16(1):1048

20. Kajuna, S.T.A.R. 2001. Millet: post-harvest operations. Food Agric. Organ. United Nations; 2001. http//www.fao.org/3/a-av009e.pdf.: 1-48.

21. Koch H, Frickel J, Valiadi M, Becks L. Why rapid, adaptive evolution matters for community dynamics. Front. Ecol. Evol. 2014;2:17 Available at https:// www.frontiersin.org/article/10.3389/fevo.2014.00017.

22. Krishnan R, Meera MS. Pearl millet minerals: effect of processing on bioaccessibility. J. Food Sci. Technol. 2018;55(9):3362-72 Available at https:// www.ncbi.n/m.nih.gov/pubmed/30150794.

23. Li H, Durbin R. Fast and accurate short read alignment with burrowswheeler transform. Bioinformatics. 2009;25(14):1754-60.

24. Linhart $Y B$, Grant MC. Evolutionary significance of local genetic differentiation in plants. Annu. Rev. Ecol. Syst. 1996;27(1):237-77 Available at https://doi.org/10.1146/annurev.ecolsys.27.1.237.

25. Mariac C, Luong V, Kapran I, Mamadou AA, Sagnard F, Deu M, Chantereau J, Gerard B, Ndjeunga J, Bezancon G, Pham JL, Vigouroux Y. Diversity of wild and cultivated pearl millet accessions (Pennisetum glaucum [L.] R. Br.) in Niger assessed by microsatellite markers. Theor. Appl. Genet. 2006;114(1):49-58.

26. Mascher M, Wu S, Amand PS, Stein N, Poland J. Application of genotypingby-sequencing on semiconductor sequencing platforms: a comparison of genetic and reference-based marker ordering in barley. PLoS One. 2013; 8(10):e76925.

27. Mohan M, Nair S, Bhagwat A, Krishna TG, Yano M, Bhatia CR, Sasaki T. Genome mapping, molecular markers and marker-assisted selection in crop plants. Mol. Breed. 1997;3(2):87-103 Available at https://doi.org/10.1023/A: 1009651919792.

28. Passot S, Gnacko F, Moukouanga D, Lucas M, Guyomarc'h S, Ortega BM, Atkinson JA, Belko MN, Bennett MJ, Gantet P, Wells DM, Guédon Y, Vigouroux Y, Verdeil J-L, Muller B, Laplaze L. Characterization of pearl millet root architecture and anatomy reveals three types of lateral roots. Front Plant Sci. 2016;7(June):1-11.

29. Pucher A, Høgh-Jensen H, Gondah J, Hash CT, Haussmann BIG. Micronutrient density and stability in west African pearl millet-potential for biofortification. Crop Sci. 2014;54(4):1709-20.

30. Safriel, U., Z. Adeel, D. Niemeijer, J. Puigdefabregas, R. White, R. Lal, M. Winslow, J. Ziedler, S. Prince, E. Archer, C. King, B. Shapiro, K. Wessels, T. Nielsen, B. Portnov, I. Reshef, J. Thonell, E. Lachman, and D. Mcnab. 2005 Dryland Systems. Washington D. C., USA.

31. Sehgal D, Skot L, Singh R, Srivastava RK, Das SP, Taunk J, Sharma PC, Pal R, Raj B, Hash CT, Yadav RS. Exploring potential of pearl millet germplasm association panel for association mapping of drought tolerance traits. PLoS One. 2015;10(5):e0122165.

32. Serba DD, Muleta KT, Amand PS, Bernardo A, Bai G, Perumal R, Bashir E. Genetic diversity, population structure, and linkage disequilibrium of pearl millet. The Plant Genome. 2019;12(3):1-12.

33. Serba DD, Yadav RS. Genomic tools in pearl millet breeding for drought tolerance: status and prospects. Front Plant Sci. 2016;7:1724.

34. Shivhare R, Lata C. Exploration of genetic and genomic resources for abiotic and biotic stress tolerance in pearl millet. Front Plant Sci. 2017;7:2069.

35. Tajima F. Statistical method for testing the neutral mutation hypothesis by DNA polymorphism. Genetics. 1989;123(3):585-95.

36. Taylor, J.R.N.B.T.-R.M. in F.S. 2016. Millet: pearl. In Reference Module in Food Science. Elsevier.

37. Varshney RK, Shi C, Thudi M, Mariac C, Wallace J, Qi P, Zhang H, Zhao Y, Wang $X$, Rathore A, Srivastava RK, Chitikineni A, Fan G, Bajaj P, Punnuri S, Gupta SK, Wang H, Jiang Y, Couderc M, Katta MAVSK, Paudel DR, Mungra KD, Chen W, Harris-Shultz KR, Garg V, Desai N, Doddamani D, Kane NA, Conner JA, Ghatak A, Chaturvedi P, Subramaniam S, Yadav OP, BerthoulySalazar C, Hamidou F, Wang J, Liang X, Clotault J, Upadhyaya HD, Cubry P, Rhoné B, Gueye MC, Sunkar R, Dupuy C, Sparvoli F, Cheng S, Mahala RS, Singh B, Yadav RS, Lyons E, Datta SK, Tom Hash C, Devos KM, Buckler E, Bennetzen JL, Paterson AH, Ozias-Akins P, Grando S, Wang J, Mohapatra T, Weckwerth W, Reif JC, Liu X, Vigouroux Y, Xu X. Pearl millet genome sequence provides a resource to improve agronomic traits in arid environments. Nat Biotechnol. 2017;35(10):969-76. 
38. Waddington S, Li X, Dixon J, Hyman G, de Vicente MC. Getting the focus right: production constraints for six major food crops in Asian and African farming systems. Food Secur. 2010;2(1):27-48.

39. Wang C, Guo L, Li Y, Wang Z. Systematic comparison of C3 and C4 plants based on metabolic network analysis. BMC Syst Biol. 2012;6(Suppl 2):S9.

40. Weir BS. Genetic data analysis II : methods for discrete population genetic data. In: Sinauer associates, Inc. Publishers. Sunderland, Massachusetts; 1996.

41. Zheng X, Levine D, Shen J, Gogarten SM, Laurie C, Weir BS. A highperformance computing toolset for relatedness and principal component analysis of SNP data. Bioinformatics. 2012;28(24):3326-8.

\section{Publisher's Note}

Springer Nature remains neutral with regard to jurisdictional claims in published maps and institutional affiliations.

Ready to submit your research? Choose BMC and benefit from:

- fast, convenient online submission

- thorough peer review by experienced researchers in your field

- rapid publication on acceptance

- support for research data, including large and complex data types

- gold Open Access which fosters wider collaboration and increased citations

- maximum visibility for your research: over $100 \mathrm{M}$ website views per year

At $\mathrm{BMC}$, research is always in progress.

Learn more biomedcentral.com/submissions 